\title{
Supply reduction policy against new psychoactive substances in China: Policy framework and implementation
}

\author{
Minqi Zhao (Criminal justice college, East China University of Political Science and \\ Law)
}

Criminal justice college, East China University of Political Science and Law, Shanghai, China

\section{A R T I C L E I N F O}

\section{Keywords:}

New psychoactive substances

NPS

Supply reduction policy

Drug policy

China

\begin{abstract}
A B S T R A C T
The global new psychoactive substances (NPS) phenomenon has been facilitated by the illicit supply thereof in China. In response, Chinese authorities updated laws and regulations, and engaged in law enforcement efforts at the national and international levels. However, what are the legal responses and how they function to reduce the illicit supply of NPS have rarely been addressed. This study aims to fill the policy gap by focusing on the design of the policy framework and the way of implementation. The study found that zero-tolerance and the state-centric policy mobilized social actors' engagement involuntarily. In addition to the passive ethos, the competing regulatory power and incentives, and economic and political contexts appear to further limit the efficiencies of law enforcement. The study concludes that focusing on deficiencies that can be corrected while considering the economic and political contexts would benefit the efforts to reduce the supply of NPS.
\end{abstract}

\section{Introduction}

China responds to NPS issues through a comprehensive approach that heavily relies on a supply reduction policy, such as modifying Criminal Law, the introduction of new regulations, updating control lists, and engaging in international law enforcement efforts to reduce the diversion of precursor chemicals and the production and distribution of NPS. Specifically, China categorized certain fentanyl analogs and 116 other NPS as controlled substances in 2015. Additionally, on March 1, 2017, China placed another four critical fentanyl analogs on the controlled substances list, including carfentanil, a particularly lethal analog (O'Donnell et al., 2017; Uddayasankar et al., 2018). The most recent update of the controlled substances list occurred on August 28, 2018, when another 32 NPS were prohibited; as a result, a total of 170 NPS (without medical values) are now under control. Subsequently, special campaigns have been openly conducted by law enforcement agencies against NPS production and distribution; this has resulted in the dismantling of several high-level criminal groups that produced and smuggled synthetic cathinones such as methcathinone and $\alpha$-PVP (Guo, 2017). These efforts were reported to effectively reduce the diversion of precursor chemicals in China on the one hand, and to decrease domestic distribution and exportation of NPS on the other (China National Narcotics Control Commission [CNNCC], CNNCC, 2016). In the two years that followed, partly due to control measures in China, some positive effects on reducing the emergence of NPS in other countries, in particular, Europe and the United States were documented (European Monitoring Center for Drugs and Drug Addiction [EMCDDA], EMCDDA, 2017; Sean, 2017).

However, the global NPS market continues to be characterized by the emergence of a large number of new substances belonging to diverse chemical groups, and the continued availability of NPS in Europe and the U.S. has been confirmed to be closely related to

E-mail address: zhaominqi180@sina.cn. 
China in which efforts to regulate NPS have been sometimes overlooked (CNNCC, 2017; EMCDDA, 2017; Sean, 2017). Related to this topic is a fundamental issue that has not been fully addressed: What are the legal framework and how it functions in response to NPS in China?

Considering the dominance of supply reduction policy in Chinese drug policy framework and its key role in reducing the production and distribution domestically and in benefiting the improvement of the efficiency of the interventions in other countries, with the exception of Zhang and Zhang (2013), H. Lu et al. (2016), and You et al. (2017), few studies have been conducted to address the details of the policy framework and how the framework functions in response to the illicit supply of NPS in China. This study seeks to fill the policy gap by detailing the supply reduction policy, the actors involved, the institutional arrangements and the way the arrangements carried out, which may be of interest for international audiences, such as policy-makers, legists, and law enforcement agencies, to have a theoretical and practical understanding of the responses against NPS in China.

\section{Ideology and objectives of the supply reduction policy}

Drug policy is heavily influenced by social and political ideology, which is an abstract, internally coherent system of beliefs or meaning (De Kort and Cramer, 1999; Mason et al., 1992). While the ideology in public opinion matters substantially in other countries (Matthew-Simmons et al., 2013), the ideology of the Communist Party of China (CPC) not only affects the development of drug policy but also guides policymaking ( $\mathrm{Wu}, 2014$ ). Thus, the supply reduction policy must be understood through the knowledge of changes in the CPC's ideology and the corresponding objectives of the supply reduction policy in historical periods.

\subsection{CPC's ideology against drugs}

The CPC's original ideology against drugs dates to 1927, when the Declaration of the Second National Congress of the Communist Party of China was issued. Here, the prevalence of opium cultivation and consumption resulted from the 'opium war' which was manipulated by the British government and merchants aiming to poison Chinese people (Qi and Li, 2008). In addition to the 'opium war,' warlordism ${ }^{1}$ was also considered to be a facilitator for the widespread opium (Qi and Zhao, 2013). In response, the CPC launched agrarian reforms to prohibit the cultivation of opium in 1930. In 1931, the Interim Soviet Criminal Law was enacted to criminalize opium-related activities, decreeing that cultivating, producing, dealing, and providing shelters for drug consumption would generally mandate a minimum of three years imprisonment to the death penalty. Legislatively, it not only symbolized the CPC's zero tolerance towards opium but also towards and imperialism and feudalism (Qi and Zhao, 2013).

During the Long March period (October 1934-October 1935), a 'mass line' policy, referring to staying with peasants and listening to their grievances to develop a solid base for fighting the Kuomintang, was developed (Troyer et al., 1989). To obtain grassroots support, the CPC's attitude regarding opium shifted from forcing to encouraging individuals to eradicate the cultivation and consumption thereof. Furthermore, the CPC tolerated and accepted drug users in the Red Army on the condition that they first joined the training camp.

After the CPC participating in the Second Sino-Japanese War, anti-narcotic drug campaigns were incorporated into its resistance against Japanese who deliberately manufactured narcotic drugs and induced Chinese people to use them (Qi and Zhao, 2013). Again, the zero tolerance ideology re-emerged as the CPC's central premise and was embodied in legislation and anti-drug campaigns. As a result, several decrees were enacted to criminalize the manufacture and distribution of drugs through severe punishment (H. Lu et al., 2016). Subsequently, zero tolerance continued to be endorsed and implemented in liberated areas after the second Sino-Japanese war.

During the early years of the People's Republic of China (PRC), guided by the zero tolerance ideology, the severe punishment and 'people's war' campaigns targeting drug manufacturers and traffickers were successful in establishing a drug-free society (Chen and Huang, 2007). However, drug problems re-emerged in the late 1970s in China. In contrast to a tolerant attitude toward drugs at an international level (McAllister, 2002), in the new era, zero tolerance continued to be implemented through increasingly formalized legislation and the CPC's efforts to build a complete and systematic legal system (H. Lu et al., 2016). Bao (2017) concluded that Chinese drug policy has always been state-oriented and implemented through stigmatizing and connecting drugs to national security. Inevitably, this leads to zero tolerance and a punitive approach.

\subsection{Objectives of the supply reduction policy}

In contrast to the back and forth of zero tolerance in previous decades (Gerring, 1997), the aim of eradicating drugs in supply reduction policy was replaced by other objectives according to the CPC's political needs. These objectives can be delineated into the following four stages.

\subsubsection{2-1949}

During this period, the CPC's political goal was to overthrow the oppression of the feudalists, warlords, and imperialists to gain

\footnotetext{
${ }^{1}$ Warlordism referred to the brief period of military and political chaos after the collapse of the Qing dynasty and the birth of the Republic of China in 1911, particularly during the period between Yuan's death in 1916 and the establishment of the Nationalist government in 1927. Bianco $(2000,293)$ called the warlords' competition to monopolize opium trade to strengthen their army "intense", and the start of the "new opium wars".
} 
complete independence for China. ${ }^{2}$ Based on the CPC's arguments that opium was a tool manipulated by feudalists, warlords, and imperialists to oppress the Chinese people, eradicating it symbolized the fight against these enemies (Qi and Zhao, 2013). Hence, the CPC prioritized eradicating drugs as a highly important goal of the social revolution, embedding it into a set of laws and regulations (Xiao, 2012). However, exceptionally, the CPC extended its zero tolerance to the maximum tolerance of opium cultivation and consumption during the Long March to augment army and auxiliary forces. In this period, the objective of the supply reduction policy changed from eradicating opium to reducing its consumption.

\subsection{2. $1950-1980$}

After the foundation of the PRC, economic development became the CPC's primary concern. As a vast agricultural country, China relied heavily on agriculture, but opium cultivation threatened the production of grain crops dramatically (Fang, 2011). For example, around 1950, 10 million farmers planted opium poppies on 20 million mu (1 mu $=0.16$ acres) of land (Su and Zhao, 1998). It was estimated, that in some heavy opium-producing regions of China such as Yunnan province, about $21 \%$ of residents were drug addicts, and $33 \%$ of its productive land was used to cultivate opium poppies (Xu, 2007). With the aim of eliminating drug related crimes and use, the Executive Administrative Ministry (EAM) issued a Decree on Banning Opium to eradicate narcotic drugs and opium within a specified time. Because of the unique economic, political, and social conditions as well as an isolated diplomatic policy during this period, the CPC could not only cut off the possibilities of drug trafficking from other countries but also eradicate domestic drug problems by strict social control and a series of anti-drug campaigns. As a result, China became a virtually drug-free society and proudly enjoyed a drug-free reputation for almost three decades (Chen and Huang, 2007; H. Lu et al., 2016; Zhou, 2000).

\subsection{3. $1981-2004$}

Responding to the re-emergence of drugs, the Decision on the Prohibition Against Narcotic Drugs (DPAND) was enacted by the National People's Congress and its Standing Committee (NPCSC) in 1990 to protect citizens' physical and mental health, maintain social security and public order, and ensure the smooth progress of the socialist modernization drive. In contrast to the previous policy focusing on opium, DPAND concentrated on opium, narcotics, and psychotropic drugs, enacting severe punishment for their manufacturing, trafficking, smuggling, or transporting. Furthermore, the NPCSC ratified the 1988 Convention and Agreement Between the Member States of the Shanghai Cooperation Organization on Cooperation in Combating Illegal Trafficking of Narcotics, Psychotropic Drugs, and their Precursors in 1989 and 2004. Both aimed to address the illicit trafficking of narcotic drugs and psychotropic substances. While zero tolerance was still central in the supply reduction policy in this stage, the objectives changed from eradicating narcotic drugs to reducing supply to protect public health and socialist modernization.

\subsubsection{4-the present}

In May 2014, the China National Narcotics Control Commission (CNNCC) adopted the Anti-drug Work Plan (2004-2008) to reduce both the demand and supply sides, and prevent the diversion of precursor chemicals in China. It also aimed to strengthen the normalization and professionalization of law enforcement agencies to improve the efficiency of anti-drug efforts. This was achieved through a strategy focusing on prevention, law enforcement, social control, and the 'four prohibitions', namely, the prohibition of cultivation, manufacture, trafficking, and consumption. In 2007, the Narcotics Control Law (NCL) was issued, which formally legalized the objective of preventing and punishing drug-related crimes so as to protect public health and social orders. Namely, the objective of existing supply reduction policy and legislation is to protect public health and social orders by reducing the illicit supply of controlled substances, such as drug-related crimes and unauthorized production.

\section{Policy framework and institutional arrangements on the supply side}

Based on the zero tolerance ideology and the objective to reduce supply, a policy framework to control NPS consisted of various institutions and arrangements has been formed.

\subsection{Legislative institutions and laws}

In response to NPS issues, legislative, administrative, and judiciary institutions have different roles concerning policymaking, legislation, and enforcement in China. As shown in Table 1, legislative institutions consist of three groups of legislators with different legislative authority. The NPCSC exercise national legislative power, including enacting and amending criminal, civil, and state laws. The Provincial People's Congress and the Standing Committee (PPCSC) of a province, autonomous region, or municipality directly under the central government enact local decrees and administrative regulations. Concerning a city's circumstances and requirements, the People's Congresses of Districted cities and their Standing Committee (PCDSC) formulate local rules concerning the enforcement of laws and regulations. The County People's Congresses and their Standing Committee (CPCSC) have no legislative power, but can engage in policymaking processes. Therefore, only the NPCSC and PPCSC have the legislative power, but all the congresses and their standing committees have policymaking authority.

The NPCSC enacted and updated several national laws that function as legal responses at the national level. As shown in Table 2, originated from the Decision on Prohibiting Narcotics Drugs in 1990, the NCL is the first comprehensive drug control law and

\footnotetext{
${ }^{2}$ Declaration of the Second National Congress of the Communist Party of China.
} 
Table 1

Regulatory design.

\begin{tabular}{|c|c|c|c|}
\hline Legislative institutions & Legislative processes & Policymaking & Policy support and implementation \\
\hline $\begin{array}{l}\text { National People's Congress and its Standing Committee } \\
\text { Provincial People's Congress and their Standing Committees } \\
\text { Municipal People's Congresses and their standing committees } \\
\text { County People's Congresses and their standing committees } \\
\text { Administrative institutions }\end{array}$ & $\begin{array}{l}\checkmark \\
\checkmark\end{array}$ & $\begin{array}{l}\checkmark \\
\checkmark \\
\checkmark \\
\checkmark\end{array}$ & \\
\hline $\begin{array}{l}\text { State Council } \\
25 \text { Departments } \\
\text { CNNCC } \\
\text { Provincial Public Security Department } \\
\text { Municipal Public Security Bureau } \\
\text { County Public Security Bureau } \\
\text { Judiciary Institutions }\end{array}$ & $\begin{array}{l}\checkmark \\
\checkmark\end{array}$ & $\begin{array}{l}\checkmark \\
\checkmark \\
\checkmark \\
\checkmark\end{array}$ & $\begin{array}{l}\checkmark \\
\checkmark \\
\checkmark \\
\checkmark \\
\checkmark\end{array}$ \\
\hline $\begin{array}{l}\text { Supreme People's Court } \\
\text { Supreme People's Procuratorate }\end{array}$ & $\checkmark$ & & $\checkmark$ \\
\hline $\begin{array}{l}\text { High people's Court } \\
\text { High People's Procuratorate }\end{array}$ & & & $\checkmark$ \\
\hline $\begin{array}{l}\text { Intermediate people's court } \\
\text { Intermediate People's Procuratorate }\end{array}$ & & & $\checkmark$ \\
\hline $\begin{array}{l}\text { Basic people's court } \\
\text { Basic People's Procuratorate }\end{array}$ & & & $\checkmark$ \\
\hline
\end{tabular}

Table 2

History of Laws enacted by NPCSC against drugs.

\begin{tabular}{llll}
\hline Previous law & Effective law \\
\hline 1990 & $\begin{array}{l}\text { Decision of the Standing Committee of the National People's Congress on the Prohibition } \\
\text { Against Narcotic Drugs }\end{array}$ & 2007 & Narcotics Control Law \\
1979 & Criminal Law & 1997 & Criminal Law and Amendments \\
1979 & Criminal Procedure Law & 2012 & Criminal Procedure Law \\
1987 & Regulations on Administrative Penalties for Public Security & 2012 & Public Security Administration Punishments \\
& & & Law \\
\hline
\end{tabular}

Table 3

Typical cases related to NPS in recent five years.

\begin{tabular}{llll}
\hline Year & Brief introduction of case & Number of offenders & Highest Penalty \\
\hline 2013 & Murder after consuming ketamine & 1 & Death \\
2015 & Manufacturing ketamine $(13.48 \mathrm{Kg})$ & 1 & Death \\
& Murder after consuming ketamine & 1 & $15 \mathrm{gears}$ imprisonment \\
2016 & Trafficking in ketamine $(2.49 \mathrm{~g})$ and ice $(5.23 \mathrm{~g})$ with guns & 1 & Death \\
2017 & Trafficking in ketamine $(4.6 \mathrm{Kg})$ and ice $(6.06 \mathrm{~kg})$ & 4 & Death \\
& Manufacturing ketamine $(125.8 \mathrm{Kg})$ & 3 & One year and eight months imprisonment \\
& Providing shelter for ketamine consumption & 4 & Eight years and six months imprisonment \\
& Manufacturing 0-Chlorphenyl Cyclopentyl Ketone $(231.5 \mathrm{Kg})$ & &
\end{tabular}

considered a milestone regarding anti-drug education, narcotics control and regulation, treatment and rehabilitation, international cooperation, and legal liabilities. It sets strict rules for the legitimate use of chemicals and controlled substances. The penalties for non-compliance are detailed in the Criminal Law and Criminal Procedure Law (CPL). There are also provisions for an administrative penalty in the Public Security Administration Punishments Law (PSAPL) regarding the illicit supply of a small number of drugs and NPS lower than the threshold of criminal sanction. This signifies the progress in reducing demand, updating the drug treatment ideology and rehabilitation (Mo and $\mathrm{Gu}, 2010$ ). However, few changes have been made regarding the supply side. Zero tolerance continues for the illicit production, distribution, and use of pharmaceuticals, chemicals, and medicines (Table 3).

Furthermore, the PPCSC in each provincial region could enact anti-drug ordinances to strengthen the implementation of national anti-drug laws at the local level. In the process of addressing the capacity to deal with the illicit supply of NPS, most provincial ordinances have been updated.

For example, the PPCSC of Yunnan province enacted the Yunnan Anti-drug Regulation (ADR) in 1991 to eradicate drugs. However, only four precursor chemicals - acetic oxide, diethyl ether, trichloromethane, and ammonia chloride-were emphasized. In contrast, updated in 2018, the ADR aims to prevent drug-related crimes to protect public health and social order through 
comprehensive responses to NPS supply in four areas: the self-regulation of qualified producers and sellers; supervision of the diversion of substances to the dark market; real-name registration systems for express consignments; and Internet censorship. The four areas are also emphasized in other provincial ordinances, such as Guangdong Anti-drug Regulation in 2015, Shanghai Anti-drug Regulation in 2016, and Shandong Anti-drug Regulation in 2018. It should be noted that these provincial ordinances appear to focus on three key features of NPS supply addressed by Seddon (2014), including transnational nature, steep trajectory, and Internet involvement.

The transnational nature refers to relations between some source countries-including China and to a lesser extent, India-and consumer countries (Seddon, 2014). One important measure by provincial legislators is to prevent the diversion of precursor chemicals and substances in the processes of production, delivery, and use. Chemical and pharmaceutical manufacturers and distributors must follow the State's provision and are obliged to establish and implement an inner management system. Carriers including logistics, postal services, and express companies are also obliged to check the consignment and valid identity documents of shippers or senders. Accordingly, administrative departments like postal services, transportation, economic, and public security organs should conduct regular and irregular inspections to monitor social actor's compliance.

To cope with the pace at which NPS are updated, provincial regulations try to strengthen the capacity to detect potential NPS by obligating administrative departments, academic institutions, medical, pharmaceutical, and chemical companies to report to the local narcotics control commissions (LNCCs) when finding new substances that can be used to manufacture NPS, or that can be addictive or misused in the future. The provincial drug control commissions must evaluate the potential risks and harms of the new substances and if necessary, report these to the CNNCC.

The role of the Internet in NPS production and distribution is also highlighted and addressed. Network service providers are obliged to monitor and prevent the spread of drug-related information such as that aiming to transfer production skills, advertising, and consumption experiences. Additionally, administrative departments should establish a coordination system to monitor illegal information and investigate drug-related behaviors on the Internet.

\subsection{Administrative institutions and arrangements}

\subsubsection{Administrative institutions}

At the national level, the State Council (SC) is the executive body of the highest organ of State power, and responsible for adopting administrative measures, enacting administrative rules and regulations, and issuing decisions and orders according to the Constitution and the law. The SC includes ministries and departments with the power to issue departmental regulations concerning NPS issues within their jurisdictions, such as China Food and Drug Administration (CFDA), National Health Commission of the People's Republic of China (NHC), and the Ministry of Public Security (MPS). To strengthen deliberation and coordination between departments, the CNNCC was established to specifically focus on drug issues. Chaired by the Minister of Public Security, it consists of 40 members from the 25 departments and other ministries. The CNNCC formulates policies and measures for drug control, coordinates relevant major issues, and guides the national drug control work.

Correspondingly, LNCCs were also established by provincial, municipal, and county governments in the early 2000s. The LNCCs' main functions are to organize, coordinate, and guide anti-drug work in their administrative regions through 1) formulating a work plan and specific measures to implement the NCL in administrative areas; 2) establishing an information sharing system; 3) organizing and coordinating control measures between member offices; 4) supervising the implementation of control measures at the local level; 5) assessing the drug situation and coordinating the solving of major problems; 6) organizing places for drug rehabilitation; and 7) executing the arrangements of and reporting to superior narcotics control commissions.

Notably, both the CNNCC and LNCCs are non-permanent departments of government, but advisory and coordinating organs which specifically address special and sudden issues by organizing and coordinating departments (Jiang, 2016). Therefore, the work of narcotics control commissions is undertaken by public security organs: the MPS at the national level, Provincial Public Security Department (PPSD), Municipal Public Security Bureau (MPSB), and County Public Security Bureau (CPSB) locally.

\subsubsection{Administrative legislation and the style of policing}

Regulations on the administration of narcotic and psychotropic drugs. The SC issued two administrative regulations to regulate NPS with medical value: the Regulation on the Control of Narcotic Drugs in 1978 and Regulation on the Control of Psychotropic Drugs in 1988. These defined narcotic drugs as toxic and possibly addictive, and psychotropic drugs as substances that directly affect the central nervous system, the continuous consumption of which might lead to dependence. In 2015, the two regulations were consolidated into administrative law, the Regulation on the Administration of Narcotic Drugs and Psychotropic Drugs (RANDPD), which was subsequently amended in 2013 and 2016. To prevent the diversion of medical products to illicit use, the RANDPD regulates activities relating to the experiment and research, production, management, use, storage, and transportation of NPS with medical value. These substances are listed in the Catalogue of Narcotic Drugs and Catalogue of Psychotropic Drugs, which were amended in 2005, 2007, and 2013, resulting in 270 controlled substances.

Regulations on the administration of narcotic drugs and psychotropic substances for non-medical use. The most recent departmental regulation focusing on NPS without medical value is the Regulation on the Administration of Narcotic Drugs and Psychotropic Substance for Non-medical Use (RANDPSN) enacted jointly by the MPS, National Health and Family Planning Commission (NHFPC, closed in 2018), the CFDA, and the CNNCC. It consists of ten articles clarifying the definition, regulation, and procedures for controlling specific NPS. To prevent illicit manufacture, distribution, use, and exportation, unauthorized supply is strictly prohibited. When issued in 2015, 116 controlled substances were noted. Subsequently, 22 new substances were added to the control list in 2017. 
The controlled substance list was last updated on August 28, 2018, prohibiting another 32 NPS, totaling 170 NPS now under control. In response to the rapid increase in new substances, RANDPSN also provides the basic procedure for assessment and regulation. For example, CNNCC may submit proposals on regulating new substances to an expert committee, which assesses the following aspects of the substances: 1) addiction or addiction potential; 2) health risks; 3) illicit manufacture, transporting, and smuggling; 4) consumption status; and 5) harm to society at the national and international level. The assessment must be completed within three months, and the results should be submitted to the CNNCC which then provides recommendations to legislators on whether the new substance should be controlled. When receiving the recommendations, the MPS, CFDA, and NHFPC list the potentially controlled NPS within six months. In urgent cases, the evaluation and control procedure can be shorter than three and six months respectively.

Based on the laws and regulations, the primary style of policing against the illicit supply of NPS is the special campaigns launched by MPS at the national level and its subordinates at the local level, which are highly praised by the Chinese authorities and scholars (Luo, 2013; Qin, 2008; Ruan, 2007; Song and Xu, 2011). A recent drug report noted that CNNCC controls NPS tightly and makes substantial efforts to investigate major cases and reduce crimes (CNNCC, 2017). Ketamine, a commonly seized and misused NPS, is heavily targeted by law enforcement agencies. Actions against ketamine are incorporated in operations targeting drug offenses. In 2016, the MPS and the CNNCC, and other law enforcement agencies involved in border control, the railways, civil aviation, forests, customs, and postal departments launched several joint campaigns against drug offenses. Examples include the 'Border Hunting Operation' by border control police, 'Iron Eagle Operation' by railway police, 'Skynet Operation' by aviation police, and the 'Green Arrow Operation' by the forest police (CNNCC, 2017). Simultaneously, the MPS initiated two operations against the illicit use of the Internet for the illicit supply of NPS, effectively curbing the rapid spread of online drug-related problems. Ultimately, in these law enforcement's initiatives against drug supply, 82.1 metric tons of drugs were seized, including 10.4 metric tons of ketamine accounting for $12.66 \%$.

In contrast to the emphasis on ketamine, other NPS were not focused on until 2015 when RANDPSN was enacted. Subsequently, the smuggling of NPS was investigated, and more than one metric ton of NPS seized in 2016, including $298 \mathrm{~kg}$ of methcathinone (CNNCC, 2017). During 2017, in a smuggling case, law enforcement agencies seized more than $200 \mathrm{~kg}$ of $\alpha$-PVP.

\subsection{Judiciary institutions}

Procuratorial and judicial institutions also play important roles in coordinating the implementation of the supply reduction policy through judicial interpretations and trials in China. The Supreme People's Court (SPC) summarized the courts' functions as implementing the CPC's drug policy, developing the effectiveness of judicial trials, strictly punishing drug offenses, and actively participating in the anti-drug drug control mechanism (Supreme People's Court [SPC], 2017).

\subsubsection{Judicial interpretations}

The SPC and Supreme People's Procuratorate (SPP) can participate in legislative processes through the case guidance system and judicial interpretations, ${ }^{3}$ both of which are not laws but have legal force. To summarize the trial experience, unify the application of the law, enhance the quality of trials, and maintain judicial justice, the case guidance system was established based on the accumulation and sublimation of Chinese judicial practical experiences (Liu and Doctor, 2017). Typical cases are selected and codified into judicial interpretation documents. Such documents have limited legal force because they should be referred to by courts when judging similar cases (X. Lu, 2014).

Judicial interpretations regarding NPS include: 1) Guidance on the Trial of Several New Drug-Related Criminal Cases (GTND) (2006); 2) Minutes of the National Courts Symposium on Trial of Drug Related Crimes (Interpretation No. 129) (2015); and 3) Several Issues concerning the Application of Law in the Trial of Drug-Related Criminal Cases (Interpretation No. 8) (2016).

The criminal courts of the SPC issued the GTND, which clarifies that punishment should be carefully meted out in NPS-related cases, and the death penalty should not be applied to NPS offenders, especially traffickers and distributors. It also unifies criteria for sentencing NPS-related cases through a heroin conversion formula (1 gram heroin $=20 \mathrm{~g}$ ketamine, $10 \mathrm{~g}$ MDMA, $1500 \mathrm{~g}$ Methaqualone, etc.).

To implement the supply reduction policy, the SPC issued Interpretation No. 129 in 2015, which focuses on the requirements for drug control trials. Four general requirements should be met when judging drug-related offenses, including strictly punishing drug crimes in accordance with the law, standardizing trials, improving the mechanism for judicial work on drug crimes, and strengthening the capability to participate in the comprehensive control of drugs. This interpretation thereof has emphasized the necessary of applying the death penalty in cases involving more than $500 \mathrm{~g}$ ketamine. However, the death penalty should not be applied to other new substances that are less harmful and have not been largely used.

The SPC issued Interpretation No. 8 in 2016, which details and standardizes the criteria for sentencing offenses related to the illicit supply of drugs, especially new substances such as fentanyl, methcathinone, and ketamine. Based on the interpretation, smuggling, trafficking in, transporting, manufacturing, or illegally possessing not less than $125 \mathrm{~g}$ of fentanyl, not less than $200 \mathrm{~g}$ of

\footnotetext{
${ }^{3}$ Article 5 of Provisions of the Supreme People's Court on the Judicial Interpretation Work, the judicial interpretations issued by the Supreme People's Court shall have full legal force. Article 5 of Notice of the Supreme People's Procuratorate on Issuing the Provisions of the Supreme People's Procuratorate on the Judicial Interpretation Work, the judicial interpretations formulated and issued by the Supreme People's Procuratorate have legal force. Where it is necessary to quote laws and judicial interpretations in the indictment, written protest, written procuratorial proposal, and any other relevant legal instrument, the people's procuratorate shall preferentially quote laws and then quote judicial interpretations.
} 
methcathinone, or not less than $500 \mathrm{~g}$ of ketamine meet the condition of 'a large amount of any other drug' prescribed in item (1) of paragraph $2^{4}$ of Article 347 and Article $348^{5}$ of the Criminal Law. This leads to more than 15-year fixed-term imprisonment and even the death penalty for the illicit supply of a large amount of NPS, and more than 7-year fixed-term imprisonment for the possession of a large amount of NPS. Interpretation No. 8 clarifies the criminal responsibility of the manufacturers and distributors who are authorized to produce, transport, and use controlled substances, but illegally provide persons such substances for consumption. The sentencing criteria regarding the diversion of legitimate substances are noted, and the amounts of substances in such crimes should be determined according to the purity of drugs.

\subsubsection{Judicial practices}

Zero tolerance is applied in judicial trials at the national and local levels. As documented by the SPC, the People's Courts implemented the drug policy by for example severely punishing drug-related crimes, increasing the penalties for the offenses of manufacturing and distributing drugs, imposing death penalties on offenders who supply drugs with armed force, and limiting the application of probation for drug offenders. In 2012, the People's Courts at all levels concluded 76,280 drug-related cases, including 81,030 offenders, which increased to 117,561 and 115,949 respectively in 2016 . In total, $21.91 \%$ of drug-related cases were sentenced to fixed-term imprisonment of not less than five years, which is far more than other criminal cases in the same period in China. The proportion is much higher in Yunnan province, which was 71.08\% between 2012 and 2016 (SPC, 2017).

\section{Revisiting the policy framework and regulatory design}

Guided by the zero tolerance ideology which originated from a semi-colonial, semi-feudal, and semi-capitalist social context, reducing drug supply through legislation, law enforcement, and judicial trials symbolizes a typical way for the implementation of supply reduction policy in China. The framework effectively eliminated narcotic drugs to build a drug-free society between 1950 and 1970 and, subsequently, continues to be endorsed as a response to the increasing supply of NPS. The existing framework centers on the NCL and is complemented by the Criminal Law, CPL, judicial interpretations, administrative laws, and departmental rules and regulations. These strengthen the legal basis for regulating NPS. The NCL defines drugs and details basic guidelines for narcotics control, rehabilitation, and administrative responsibility. The catalogs of controlled NPS and application for legitimate use are scattered in administrative laws such as RANDPD and RAPC, and departmental regulations such as RANDPSN. Penalties for violating such provisions are included in the Criminal Law, CPL, and PSAPL. The comprehensive system has achieved some success in curbing the speed at which NPS are updated in China and other countries, cracking typical cases and seizing hundreds of metric tons of NPS, specifically ketamine, synthetic opioids, and synthetic cathinone (CNNCC, 2017).

However, re-revisiting the design of the policy framework reveals many problems in the criteria for criminal sanction, division of regulatory power, and actors' limited capacity.

\subsection{Ideological and legal conflicts in policy framework design}

An ideological conflict exists between the doctrine of severe punishment and argument for light punishment. As mentioned, China enacts a zero tolerance drug policy. As a result, harsh penal punishment including the death penalty in NPS-related cases accounts for a high proportion (SPC, 2006). With a conservative attitude regarding applying severe punishment in NPS-related cases, however, the GTND seems to operate no longer within the zero tolerance spectrum. Consequently, as Yuan and He (2012) confirmed, judges are conservative regarding imposing the death penalty on NPS offenders. In contrast, Article 347 in the Criminal Law and Article 1 of Interpretation No. $8^{6}$ leave large room for imposing the death penalty on offenders with regard to the illicit supply of NPS.

For example, based on the GTND, $20 \mathrm{~g}$ of ketamine (regardless of the purity) is equivalent to $1 \mathrm{~g}$ of Heroin. This means that the sentences for trafficking $180 \mathrm{~g}$ of ketamine should be the same as trafficking $9 \mathrm{~g}$ of Heroin, namely fixed-term imprisonment of a maximum of three years according to paragraph $4^{7}$ of Article 347 in the Criminal Law. However, trafficking the same amount of

\footnotetext{
${ }^{4}$ Item (1) of paragraph 2 of Article 347 of the Criminal Law: whoever smuggles, traffics in, transport or manufactures narcotic drugs and falls under any of the following categories, shall be sentenced to fixed-term imprisonment of 15 years, life imprisonment or death and also to confiscation of property: (1) persons who smuggle, traffic in, transport or manufacture opium of not less than $1000 \mathrm{~g}$, heroin or methylaniline of not less than $50 \mathrm{~g}$ or other narcotic drugs of large quantities.

${ }^{5}$ Article 348 of the Criminal Law: whoever illegally possesses opium of not less than $1000 \mathrm{~g}$, or heroin or methylaniline of not less than $50 \mathrm{~g}$, or any other narcotic drugs of large quantities shall be sentenced to fixed term imprisonment of not less than seven years or life imprisonment and shall also be fined; whoever illegally possesses opium of not less than $200 \mathrm{~g}$ but less than $1000 \mathrm{~g}$, or heroin or methylaniline of not less than $10 \mathrm{~g}$ but less than $50 \mathrm{~g}$ or any other narcotic drugs of relatively large quantities shall be sentenced to fixed-term imprisonment of not more than three years, criminal detention or public surveillance and shall also be fined; if the circumstances are serious, he shall be sentenced to fixed-term imprisonment of not less than three years but not more than seven years and shall also be fined.

${ }^{6}$ Article 1 translation: Smuggling, trafficking in, transporting, manufacturing, or illegally possessing the following amounts of drugs shall be determined to meet the condition of "a large amount of any other drug" as prescribed in item (1) of paragraph 2 of Article 347 and Article 348 of the Criminal Law: .... (3) Not less than $125 \mathrm{~g}$ of fentanyl. Not less than $200 \mathrm{~g}$ of methcathinone ....

${ }^{7}$ Paragraph 4 translation: Whoever smuggles, traffics in, transports or manufactures opium of less than $200 \mathrm{~g}$, or heroin or methylaniline of less than $10 \mathrm{~g}$ or any other narcotic drugs of small quantities shall be sentenced to fixed-term imprisonment of not more than three years, criminal detention or public surveillance and shall also be fined; If the circumstances are serious, he shall be sentenced to fixed-term imprisonment of not less
} 
ketamine mandates imprisonment of at least seven years according to Article $2^{8}$ of Interpretation No. 8 and paragraph $3^{9}$ of Article 347 in the Criminal Law.

In addition to the conflicts in ideology and criteria concerning the judicial interpretations, another question is: are judicial interpretations qualified to authorize criminal penalty? Most Chinese scholars insist that judicial interpretations should be a supplementary interpretation of Criminal Law, rather than creating new standards for conviction and sentencing (Liu, 2007). However, in response to the recent emergence and rapid increase of NPS, there appears to be insufficient time for legislators to revise the Criminal Law and NCL. Consequently, judicial interpretations have been widely applied to guide judicial practice, among which, some exceed their authorities by creating new criteria for sentencing NPS-related offenses.

Conflicts also exist between Criminal Law and prepositional decrees. Article 357 of the Criminal Law defines narcotics as narcotic and psychotropic substances under State regulations. According to Article 96 of the Criminal Law, State regulation refers to the laws enacted or decisions made by the NPCSC, which excludes SC's administrative laws, departmental ordinances, and orders. Essentially, the Criminal Law restricts the level of authority of prepositional laws that define the scope of narcotic drugs. However, RANPSN was issued by the SC, and RANDPSN by departments of the SC. Both are not State regulations, and cannot be referred to by Criminal Law. Bao (2017) explains that these laws and regulations should not be referred to when defining narcotic drugs in Criminal Law, because they are not justified by law.

\subsection{Competing incentives and overlaps in the implementation process}

In addition to ideological and legal conflicts, the competing incentives between levels of government within the dual leadership in the bureaucratic system may limit the capacity of enforcers.

The relationships between the central government and local authorities refer to how state administration at the top, middle, and bottom levels operates. The basic model governing the Chinese government's current operations is 'central decision-making, local implementation' (Xuan, 2017). State administration is underlined, while local governments are also highlighted because of their distinctive characteristics in promoting the governance at provincial, municipal, and county-level in history. However, the CPC considers the duality of 'center' and 'region' a contradiction; thus, there has been a periodic swing between centralization and decentralization (Schurmann, 1971). In the late 2000s, decentralization was advocated to encourage local authorities' participation in advancing local economic growth. Two problems exist in this process: increasing autonomy for local authorities and limited constraints from the central government (Z. Zheng, 2018).

Inside the 'central decision-making, local implementation,' the CPC stresses administration through inter-branch coordinative agencies and decentralization, resulting in a dual leadership system. Herein, administrative units are linked hierarchically according to functional principles. Namely, all units with similar operations form a single branch in which a ministry operates a hierarchy of regional bureaus and enterprises (Schurmann, 1971). Administrative units are also linked with the regional authority at its level. For example, administratively, the narcotics control commission at the municipal level is responsible for the municipal government but, functionally, it is responsible for the provincial narcotics control commission. However, at the central level, the power of the coordinating committee (such as CNNCC) is often hindered by the government's branch agencies (such as MPS), namely the big ministries. In contrast, the branch organization at the local level is weaker, and the big local governments are dominated by CPCSCs (He, 2011). Therefore, once local governments gained control of an industrial sector, it was difficult for the industrial ministry to maintain the jurisdiction it still had over that sector.

Regarding NPS control, at the national level, the CNNCC was established to guide and coordinate drug control in China, but its work is undertaken by the MPS. Here, the CNNCC is weakened and incorporated into the big MPS at the national level. As shown in Table 4, while the MPS is authorized to engage in policymaking and supervising all NPS, the CNNCC and LNCCs are only authorized to monitor NPS without medical value. At the local levels, LNCCs are weakened and incorporated into the public security organs which mainly serve the big local governments rather than their supreme organization, the CNNCC. Therefore, the relationships between local governments and the central government, in particular, the ministries, seem to be critical for the implementation of the supply reduction policy in practice.

However, the competing incentives between the central and local governments in the 'central decision-making, local implementation' and dual leadership system are frequently noticed. For example, the implementation of the supply reduction policy heavily relies on local governments to strictly regulate the chemical and pharmaceutical industries. This increases the reluctance of local officials given that revenues from these industries are quite important for the local economy which is closely linked with local officials' career opportunities. Therefore, the development of the economy has become a major concern for local officials (Yu, 2015). This creates a dilemma regarding economic development and the implementation of the supply reduction policy. In fact, local

\footnotetext{
(footnote continued)

than threes but not more than seven years and shall also be fined.

${ }^{8}$ Article 2 translation: Smuggling, trafficking in, transporting, manufacturing, or illegally possessing the following amounts of drugs shall be determined to meet the condition of "a relatively large amount of any other drug" as prescribed in paragraph 3 of Article 347 and Article 348 of the Criminal Law: .... (7) Not less than $100 \mathrm{~g}$ but below $500 \mathrm{~g}$ of ketamine.

${ }^{9}$ Paragraph 3 translation: Whoever smuggles, traffics in, transports or manufactures opium of not less than $200 \mathrm{~g}$ but less than $1000 \mathrm{~g}$, or heroin or methylaniline of not less than $10 \mathrm{~g}$ but less than $50 \mathrm{~g}$ or any other narcotic drugs of relatively large quantities shall be sentenced to fixed-term imprisonment of not more than seven years and shall also be fined.
} 
Table 4

Division of regulatory power.

\begin{tabular}{lll}
\hline & NPS with medical value & NPS without medical value \\
\hline \multirow{2}{*}{ National Policymaker } & MPS & MPS \\
& CFDA & CFDA \\
National Supervisor & NHC & MPS \\
& MPS & CNNCC \\
Local Policymaker & CFDA & PPCSC \\
& PPCSC & MPCSC \\
Local Supervisor & MPCSC & PPSD \\
& PPSD & PPSD \\
\hline
\end{tabular}

officials prefer to use fewer administrative regulations within their autonomies to provide more space for companies and their business activities to develop ( $Y$ u, 2016). Subsequently, local economies develop, revenues grow quickly, and local officials have increased career opportunities in the political system at the cost of the implementation of supply reduction policy (He and Sun, 2012).

Similar competing incentives are also noticed between the social actors and the governments, reflected by the unwillingness of social actors engaging in the 'war on drugs.' Thus, national and provincial legislators remain obsessed with state-centric 'command and control' approaches to mobilize various social actors to join the 'web of control' by imposing legal duties on them. Seemingly, unbalanced duties and rights—-the lack of a reward system-dampens social actors' voluntariness to play their roles actively. Cheng (2010) noted that most logistics companies do not strictly follow the protocol to verify parcels and check senders' identities, which could improve the efficiency of express mail and attract more clients.

\section{Economic and political facilitator}

Till now, we have acknowledged the comprehensive legal responses, the way of being carried out, and the regulatory deficiencies. Considering the legal responses are developed under certain political and economic contexts, it is necessary to take a further insight into the economic and political facilitators to see how they shape the supply reduction policy and its implementation. However, the roles of economy and polity are by no means the same. Rather, there seem to be many changes in legislation that are affected by the changes in polity caused by the development of the market economy in modern Chinese society. Namely, the economy is allowed to penetrate other institutions, such as polity and law that are less capable of providing stakes in conformity in the form of meaningful social roles (Savolainen, 2000).

\subsection{The economic influence on the regulation and its implementation}

In 1978, the Third Plenary Session of the Eleventh Central Committee officially highlighted that the principal contradiction in China was no longer class struggle but a contradiction between the growing material and cultural needs of the people and the backwardness of social production (Leng, 1985). The shift of the contradiction provides a solid ground for the establishment of the open door policy in December 1978. The pilot projects of the open door policy consisted of establishing several special economic zones in which foreign investment was welcomed, the market operation was introduced, and enterprises were given a series of preferences, such as tax breaks and exemptions, land use privileges, and duty exemptions. The success of the pilot projects paved a way for the expansion of the market economy which co-exists with the planned economy and officially named as the socialist market economy with Chinese characteristics. With the development of the economic reforms and the open door policy, not only China's economic structure but also the legal system was transformed (H. Lu et al., 2016).

First, the market economy has developed and changed China's economic structure. In order to increase economic productivity to relieve the principal contradiction, several major changes in economic structure have been made in both rural and urban areas. In rural areas, the collective production system has been partly replaced by a household contract responsibility system that entrusts the production and management of public-owned farmland to individual households through long-term contracts. This change greatly promoted farmers' incentives and resulted in a substantial increase in agricultural production. At the same time, in urban areas, nonstate-owned enterprises, such as private enterprises and joint ventures, were also introduced into the planned economy structure, resulting in major economic shifts away from the socialist patterns, which contributes to the dramatic urban transformation during the reform-era (Lin et al., 1996; Ma, 2002). The new production modes in both rural and urban, namely the household contract responsibility system and the non-state-owned industries increased dramatically in the following years. For example, from 1978 to 2005, the gross output value of agricultural production increased from CNY 111.76 billion to CNY 1.96 trillion (H. Lu et al., 2016). By the mid-1980s, the number of non-state-owned industries exceeded the total number of state- and collective-owned industries (public-owned-industries). Due to their rapid expansion, non-public-owned industries started absorbing more and more laborers and contributed more and more shares to China's total GDP. Official data show that non-public-owned economies already annually contributed more than $50 \%$ of China's total GDP, invested more than $60 \%$ of China's total investment, created more than $70 \%$ of the technical innovation and new products, and generated more than $80 \%$ job opportunities. The rapid growth and the huge success of 
the market economy over the planned economy have changed the internal structure of Chinese economy from a planned economy to a market economy in a stable fashion (Guthrie, 2012).

Second, the development of the market economy has also encouraged the start of legal reform in China. Due to the important role of non-public-owned sectors in promoting the economy and relieving the principal contradiction, the Chinese government realized that it was necessary to start the legal reform to protect and further promote the economic reforms and to maintain social stability (Liang, 2008). In 1999, the socialist market economy consisted of state-owned-industries and non-state-owned sectors was first legalized by the amendment of the national Constitution. This reform provided a legal ground for the development of non-state-owed sectors, such as individual chemical and pharmaceutical manufacturers and various companies, and further encouraged the development of the market economy. As a result, China becomes a global manufacturing center, in which more than 5000 manufacturers produce more than 2000 produces and around 400,000 chemical manufacturers, with an annual production capacity of more than two million tons pharmaceutical ingredients and countless chemicals (Pardo, 2018). However, there have been many problems concerning the production and use of chemicals and substances. For example, there are a lot of manufacturing facilities in operation producing a huge amount of chemicals and new substances without legal approval. As responses to these deviant behaviors in the market economy, the RAPC was enacted in 2005 to prevent the diversion of chemicals to drug production. Since then, 27 chemicals have been banned at the national level. At the same time, the RANDPD was also enacted to regulate the supply of psychoactive substances with medical value. Later in 2015, the RANDPSN was also enacted to regulate the diversion of NPS without medical value. Thus, the development of the market economy not only contributes to the economic structure but also shapes the improvement of the regulation system.

Third, the ideological transformation generated from the development of the market economy has also shaped the implementation of the law. Along with the economic and legal changes was an ideological transformation from the old ideology under Mao's control to new ideas, values, and lifestyles among younger generations (Cao and Hou, 2001). With the deepening of the transformation, for example, getting rich was no longer shameful but glorious, and people were willing to take any means to be rich, including committing crimes (Rojek, 2001). At the same time, the market economy and economic reforms intensified social economic competition and opened up opportunities for gaining profit by violating social norms, rules, and regulations. For example, drug trafficking has been such a means, and gaining profit was the primary reason. In addition, there are some deviant behaviors resulting from the conflict between economic motivation and regulations. Qin and Zhao (2007) found out that many chemicals producers find the approval system to be strict, cumbersome, and bureaucratic, which, in turn, affects the autonomy and flexibility of the operations of their companies. Therefore, some chemical, pharmaceutical, and biotechnological companies, especially individuals and small companies encountering difficulties in applying for licenses in local administrative departments, may continue to produce and sell chemicals without licenses (Qiu, 2006). In other cases, to exploit the differing legal status of chemicals, some chemical and pharmaceutical companies further attempted other innovations to synthesize pre-precursors and precursors from various kinds of medicines and legal chemicals to circumvent the laws and law enforcement, which further manifests the low efficiencies of supply reduction policy (Zhao, 2018).

\subsection{Political influence on enforcement}

The development of the market economy has also contributed to the political transformation which further impacts the role of local officials in implementing drug control policy. In the pre-reform era, the principal contradiction was class struggle. In response, the CPC held exclusive political and institutional power over the country. In practice, the CPC and the state were overlapped in almost every aspect of governance and all top positions were occupied by communist party members, which further enhanced the party's power. However, in the reform era, the principal contradiction was between the growing material and cultural needs of the people and the backwardness of social production, and a solution to such a contradiction was economic growth. Because of the important role of non-state-owned industries in urban and rural areas, the central government has tried several strategies to mobilize local officials to devote themselves to local economic construction.

First is a decentralized fashion in the political system. The Chinese society in Mao's era was often referred to as a totalitarian regime under which political pressure, secret police surveillance, and intensive mass campaigns initiated by Mao were the primary tools to control the polity, economy, and society. At this stage, as noted by Walder $(1986,1995 a, 1995 b, 1995 c)$, the institutional mechanisms that served to maintain order within Chinese political system mainly included organized dependence (the dependence of subordinates on their superiors for the satisfaction of needs and career opportunities), monitoring capacity (the capacity of superiors to obtain information about the activities of subordinates), and sanctioning capacity (the ability to reward or punish the political behavior of subordinates). These relationships functioned as a bedrock on which the CPC institutionalized control over society and maintained the stability of state power. With the development of the capacity of individuals and local government in building the economy, such institutional mechanisms have been weakened. Hence, the CPC tried to move way from strict social control and direct decision making towards a decentralized fashion so that the local officials could lend a 'helping hand' in advancing local economic growth (Alon et al., 2009).

Second is the economic and political incentives to motive local officials. In order to motivate local officials' willingness to advance the economy, the central government has begun to decentralize the fiscal system in 1980, so that the central and local governments would share fiscal revenues. As a result, local officials adopted diverse strategies in an attempt to build local infrastructure, encourage local businesses, and attract foreign investment to develop the local economy. In addition, the central government also incorporated economic achievement into the political promotion system. Namely, the development of the local economy has been an important parameter for evaluating officials' career achievement. Many academics have noted that the readiness of the Chinese central 
government to reward or punish local officials is mainly based on their economic performances, which motivates them to promote the local economy (Blanchard and Shleifer, 2001; Li and Zhou, 2005). Consequently, local economic development has been closely linked with the promotion system and has correspondingly become a main concern for local officials (Yu, 2015). Partly due to such incentives, local authorities have been increasingly played various active roles in the local economy to gain competitiveness in the political promotion system (Ma, 2002).

However, after China's regulation of precursor chemicals and NPS, substantial amounts of precursor chemicals and pharmaceutical products have been rejected for export. In addition, special campaigns are frequently required by the central government to check the compliance of chemical and pharmaceutical companies at the local level. It is plausible that the regulation of the chemical and pharmaceutical production could largely impact the supply chain and further affect the local economy negatively. Given the close relationship between the local economy and political incentives, local officials may prefer to prioritize the local economy rather than targeting on deviant behaviors and crimes.

\title{
6. Conclusion
}

In this study, we were primarily concerned about the details of the supply reduction policy against NPS in China, including their ideology, objectives, and regulatory framework. Simultaneously, how the policy is implemented in a complex structure of parallel bureaucracies is also presented by describing the division of regulatory authority, the function of different actors at both national and local levels. It seems that a comprehensive framework has been developed, whereby the aim of reducing the supply should be achieved. However, many regulatory deficiencies are underlined concerning the division of regulatory power and the way of implementation. Among them, some can be corrected, such as the overlaps between different regulators; while others are impossible to be overcome but could be controlled, such as the conflict between the emergence of new substances and the hysteresis quality of law, and the conflicts between different laws, and the competing incentives between levels of government. At the same time, economic and political contexts also affect and shape the supply reduction policy and its implementation, which appears to suggest that further develops regarding the regulatory design should also take these contexts into account.

\section{Declaration of competing interest}

The author declares that there are no conflicts of interest.

\section{Acknowledgements}

The author would like to thank Dirk J. Korf and Charlotte Colman, for their critical comments on the daft.

\section{Appendix A. Supplementary data}

Supplementary data to this article can be found online at https://doi.org/10.1016/j.ijlcj.2019.100374.

\section{References}

\author{
Alon, I., Chang, J., Fetscherin, M., Lattemann, C., McIntyre, J., 2009. China Rules: Globalization and Political Transformation. Springer, New York. \\ Bao, H., 2017. On the concept of drugs and the principle of the list by authorization. J. Beijing Union Univ. 3. \\ Blanchard, O., Shleifer, A., 2001. Federalism with and without political centralization: China versus Russia. IMF Staff Pap. 48 (1), $171-179$. \\ Cao, L., Hou, C., 2001. A comparison of confidence in the police in China and in the United States. J. Crim. Justice 29 (2), 87. \\ Chen, Z., Huang, K., 2007. Drug problems in China: recent trends, countermeasures, and challenges. Int. J. Offender Ther. Comp. Criminol. 51 (1), 98-109. \\ Cheng, X., 2010. An analysis of preventing drug trafficking in the South of Yunnan. J. Adm. Law 5, 35-39. \\ CNNCC, 2016. Annual Report on Drug Control in China. . http://www.nncc626.com/2016-11/21/c_129372086.htm. \\ CNNCC, 2017. Annual Report on Drug Control in China. . http://www.nncc626.com/2017-03/30/c 129521742.htm. \\ De Kort, M., Cramer, T., 1999. Pragmatism versus ideology: Dutch drug policy continued. J. Drug Issues 29 (3), $473-492$. \\ EMCDDA, 2017. European Drug Report 2017: Trends and Developments. Publications Office of the European Union, Luxembourg. \\ Fang, Y., 2011. Research of the Anti-drug Legal (1950-1952). (Doctor). Southwest University of Political Science and Law, Chongqing. \\ Gerring, J., 1997. Ideology: a definitional analysis. Political Res. Q. 50 (4), 957-994. \\ Guo, S., 2017. Research on the Precaution and Control Measures of New Psychoactive Substances. (Master's Thesis). People's Public Security University of China, \\ Beijing. \\ Guthrie, D., 2012. China and Globalization: the Social, Economic and Political Transformation of Chinese Society. Routledge, New York. \\ He, C., 2011. Anti-drug storm on taihang mountain. People's Police 17, 2. \\ He, C., Sun, Z., 2012. Logic of political turnover: evidence from prefectural mayors in China. Econ. Issues China 6, 13-24. \\ Jiang, Y., 2016. Dilemma and transcendence of local advisory and coordinating institutions. J. Huaihai Inst. Technol. (Nat. Sci. Ed.) 1, 5. \\ Leng, S., 1985. Criminal Justice in Post-Mao China: Analysis and Documents. State University of New York Press, Albany. \\ Li, H., Zhou, L.-A., 2005. Political turnover and economic performance: the incentive role of personnel control in China. J. Public Econ. 89 (9-10), 1743-1762. \\ Liang, B., 2008. The Changing Chinese Legal System, 1978-present: Centralization of Power and Rationalization of the Legal System. Routledge, New York. \\ Lin, J.Y., Cai, F., Li, Z., 1996. The China Miracle: Development Strategy and Economic Reform. Chinese University Press, Hong Kong. \\ Liu, Y., 2007. Research on the time validity of criminal law interpretation. Crim. Sci. 3, 74-79. \\ Liu, Y., 2017. The Study of Criminal Case Guidance System (Doctor). Jilin University, Jilin. \\ Lu, X., 2014. The legal force of case guidance issued by Supreme People's Court. Law Sci. 9, 6. \\ Lu, H., Miethe, T.D., Liang, B., 2016. China's Drug Practices and Policies: Regulating Controlled Substances in a Global Context. Routledge, London. \\ Luo, G., 2013. Problems and solutions on xinjiang new-type drug crime. J. Yunnan Police Officer Acad. 4. \\ Ma, L.J., 2002. Urban transformation in China, 1949-2000: a review and research agenda. Environ. Plan.: Econ. Space 34 (9), $1545-1569$.
}


Mason, D.T., Lusk, M.W., Gintzler, M., 1992. Beyond ideology in drug policy: the primary prevention model. J. Drug Issues 22 (4), $959-976$.

Matthew-Simmons, F., Sunderland, M., Ritter, A., 2013. Exploring the existence of drug policy 'ideologies' in Australia. Drugs Educ. Prev. Policy 20 (3), $258-267$. McAllister, W.B., 2002. Drug Diplomacy in the Twentieth Century. Routledge, London.

Mo, G., Gu, K., 2010. Circumstances of drug prohibition works under drug control law. J. Kunming Univ. Sci. Techonol. 6.

O'Donnell, J.K., Halpin, J., Mattson, C.L., Goldberger, B.A., Gladden, R.M., 2017. Deaths involving fentanyl, fentanyl analogs, and U-47700-10 states, July-December 2016. Morb. Mortal. Wkly. Rep. 66 (43), 1197.

Pardo, B., 2018. Evolution of the US Overdose Crisis. https://www.rand.org/content/dam/rand/pubs/testimonies/CT400/CT497/RAND_CT497.pdf.

Qi, J., Li, Y., 2008. Anti-narcotic drug capaign of comunist party of China. J. Yunnan Inst. Soc. 5, 5.

Qi, J., Zhao, Y., 2013. The major contribution of the communist party of China to China's and world's anti-drug cause. Studies on Mao Zedong and Deng Xiaoping Theories. 4. pp. 8.

Qin, Z., 2008. A study on changes of new drugs related crimes and responses. J. Political Sci. Law 25, 70-74.

Qin, Z., Zhao, T., 2007. On existing problem and str ategy on the regulation of poisonable chemicals. J. Xinjiang Police Officers' Acad. $27,4$.

Qiu, Z., 2006. On the characteristics and preventive measures of crimes of easily-made drug chemicals. J. Political Sci. Law 23.

Rojek, D.G., 2001. "Chinese social control: from shaming and reintegration to 'getting rich is glorious. Crime and Social Control in a Changing China, vols. 89-104 Greenwood, Westport.

Ruan, H., 2007. On crmie situations of the illicit new-type drugs in yunnan province as well As on its strategic research. J. Yunnan Police Officer Acad. 62.

Savolainen, J., 2000. Inequality, welfare state, and homicide: further support for the institutional anomie theory. Criminology 38 (4), $1021-1042$.

Schurmann, F., 1971. Ideology and Organization in Communist China. Univ of California Press, California.

Sean, O.C., 2017. Fentanyl: China's Deadly Export to the United States. https://www.uscc.gov/Research/fentanyl-china\%E2\%80\%99s-deadly-export-united-states.

Seddon, T., 2014. Drug policy and global regulatory capitalism: the case of new psychoactive substances (NPS). Int. J. Drug Policy 25 (5), 1019-1024. https://doi.org/ 10.1016/j.drugpo.2014.03.009.

Song, Q., Xu, J., 2011. Research on new drug related crimes and legal responses. J. Intell. 30, 61-67.

SPC, 2006. Model Cases of Drug-Related Crimes Induced by the Supreme People's Court. http://www.gov.cn/govweb/jrzg/2007-06/25/content_661498.htm.

SPC, 2017. White Paper of People's Court on Drug Control. http://cq5zy.chinacourt.org/article/detail/2017/06/id/2900500.shtml.

Su, Z., Zhao, C., 1998. Treaties of War on Drugs. China Democracy and Law Publishing House, Beijing.

Troyer, R.J., Clark, J.P., Rojek, D.G., 1989. Social Control in the People's Republic of China. Praeger Publishers, New York.

Uddayasankar, U., Lee, C., Oleschuk, C., Eschun, G., Ariano, R.E., 2018. The pharmacokinetics and pharmacodynamics of carfentanil after recreational exposure: a case report. J. Human Pharmacol. Drug Therapy 38 (6), e41-e45.

Walder, A., 1986. Communist Neo-Traditionalism: Work and Authority in Chinese Industry. University of California Press, Berkeley and Los Angeles.

Walder, A., 1995a. Career mobility and the communist political order. Am. Sociol. Rev. 60, 309-328.

Walder, A., 1995b. The quiet revolution from within: economic reform as a source of political decline. In: Walder, Andrew (Ed.), In the Waning of the Communist State. vols. 1-24 University of California Press, Berkeley and Los Angeles.

Walder, A., 1995c. The Waning of the Communist State: Economic Origins of Political Decline in China and Hungary. University of California Press, Berkeley and Los Angeles.

Wu, R., 2014. Research on drug policy of China communist party. J. Yunnan Inst. Soc. 7, 88-92.

Xiao, H., 2012. The research on the drug-fighting statutes of north China anti-Japanese base area and liberated area. J. Heibei Univ. 2 , 6.

Xu, Y., 2007. Drug prohibitions in qinhuai. Wenshi Jinghua 5, 4.

Xuan, X., 2017. The adjustment of central local relations and the advancement of regional synergistic development. Reg. Econ. Rev. 6, 11. https://doi.org/10.14017/j. cnki.2095-5766.2017.0196.

You, Y., Deng, Y., Zhao, M., 2017. Research on Third generation drug: growing trend assessment, bottleneck of regulation and countermeasure of NPS. J. Sichuan Police Coll. 29, 97-102.

Yu, X., 2015. The analysis of the promotion system in China. J. Jiangxi Adm. Inst. 17, 44-50.

Yu, X., 2016. Official promotion tournament: political logic of economic growth — based on sorting and analysis of the relevant literature. East China Econ. Manag. 30 , 88-95.

Yuan, x., He, r., 2012. Research on the death penalty of new drug related cases. J. Yunnan Univ. Law Ed. 25.

Zhang, L., Zhang, T., 2013. Research on the challenges of new psychoactive substances and its prevention. In: Journal of People's Public Security University of China (Social Sciences Edition), pp. 64.

Zhao, M., 2018. The Illicit Distribution of Precursor Chemicals in China: A Qualitative and Quantitative Analysis. International Journal for Crime, Justice, and Social Democracy. (accepted).

Zheng, Z., 2018. An analysis of the local rule of law experiment-from the perspective of relations between local and central government. Law Soc. Dev. 5, 18.

Zhou, Y., 2000. Nationalism, Identity and State Building: the Anti Drug Crusade in the People's Republic, 1949-1952. Opium Regimes, China, Britain and Japan, pp. 380-404 1952. 